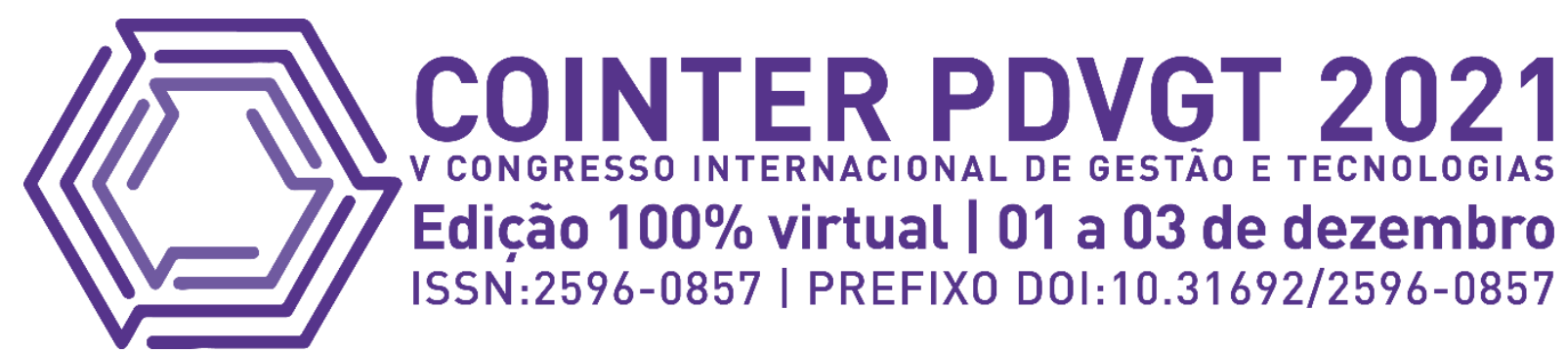

\title{
REMEDIAÇÃO DE EFLUENTE INDUSTRIAL EM LAVANDERIAS DO POLO TÊXTIL NO AGRESTE PERNAMBUCANO
}

\section{REMEDIACIÓN DE EFLUENTE INDUSTRIAL EN LAVANDERÍAS DEL POLO TEXTIL EN AGRESTE PERNAMBUCANO}

\section{REMEDIATION OF INDUSTRIAL EFFLUENT IN LAUNDRUES OF THE TEXTILE POLO IN AGRESTE PERNAMBUCANO}

\author{
Apresentação: Comunicação Oral \\ Juliana Rafaela Silva Alves ${ }^{1}$; Adriel Roberto Ferreira de Lima²
}

DOI: https://doi.org/10.31692/2596-0857.IVCOINTERPDVGT.0078

\begin{abstract}
RESUMO
Lavanderias indústrias são responsáveis pelo beneficiamento de peças jeans que passam por processos químicos e físicos gerando assim cargas poluidoras que contribuem para o atual status da indústria têxtil de segundo setor mais poluente do meio ambiente. A remediação dessas cargas é imprescindível para o reaproveitamento da água ou para o despejo. Sendo assim, foi observado na literatura científica possíveis formar de mitigar essa carga poluidora, também foi realizado entrevistas com cinco lavanderias (A, B, C, D e E) dentro do Agreste Pernambucano juntamente com a aplicação de um questionário para fazer o levantamento de dados dos métodos já utilizados por estas, qual o grau de eficiência e qual seria o destino final tanto do lodo residual quanto da água tratada. O sistema de tratamento aplicado na ETE de algumas dessas lavanderias é o sistema por processo contínuo, além desse processo ainda existe o por batelada. Essas empresas costumam utilizar para fazer o tratamento do seu efluente equipamentos e materiais como: Compressor, bomba, tanques, agentes químicos, Filtro de areia. O tempo de remoção da carga varia em cada lavanderia, na empresa A em 20 minutos são tratados 10 mil litros; na B entre 1hora e 1hora e meia são tratados 15 mil litros; a empresa $C$ trata em 45 minutos 20 mil litros; a $D$ em 1hora trata 120 mil litros e a lavanderia $E$ não pode informar por não ter ou não poder estimar um tempo. Foram realizados coleta de amostras do efluente de entrada e saída nas Lavanderias A e B para medição do $\mathrm{pH}$ e da turbidez, constatou-se que o pH de entrada e saída do estabelecimento A foi de 3.77 e 6.80 respetivamente, enquanto a média da turbidez de entrada foi de 9,37 NTU e saída de 1,9 NTU. Já o empreendimento B teve seu $\mathrm{pH}$ de entrada e saída equivalente a 5.59 e 4.51 respetivamente, e a sua média de turbidez de entrada de 111,3 NTU e 3,13 NTU de saída. Esses dados potencializam e sintetizam a pesquisa de modo que possibilita a comparação dos resultados das práticas industriais com as indicações já estabelecidas pelas normativas.
\end{abstract}

Palavras-Chave: Indústria têxtil, Remediação de efluente, Agreste Pernambucano, Sustentabilidade, Corante Industrial.

\section{RESUMEN}

Las lavanderías industriales son las encargadas de procesar piezas de mezclilla que se someten a procesos químicos y físicos, generando así cargas contaminantes que contribuyen al estado actual de la

\footnotetext{
${ }^{1}$ Engenharia Mecânica, Instituto Federal de Pernambuco, jrsa.@ dicente.ifpe.edu.br

${ }^{2}$ Professor Doutor, Instituto Federal de Pernambuco, adriel.lima@ caruaru.ifpe.edu.br
} 
industria textil como el segundo sector más contaminante del medio ambiente. La remediación de estas cargas es fundamental para la reutilización del agua o para su eliminación. Así, se observó en la literatura científica posibles formas de mitigar esta carga contaminante, también se realizaron entrevistas a cinco lavanderías (A, B, C, D y E) dentro del Agreste Pernambucano junto con la aplicación de un cuestionario para relevar datos sobre los métodos ya utilizados por ellos, cuál es el grado de eficiencia y cuál sería el destino final tanto de los lodos residuales como del agua tratada. El sistema de tratamiento aplicado en el ETE de algunas de estas lavanderías es el sistema de proceso continuo, además de este proceso, también está el proceso por lotes. Estas empresas suelen utilizar equipos y materiales como: Compresor, bomba, tanques, agentes químicos, filtro de arena para tratar sus efluentes. El tiempo de retirada de la carga varía en cada lavandería, en la empresa A se tratan 10 mil litros en 20 minutos; en B entre 1 hora y 1 hora y media se tratan 15 mil litros; la empresa $C$ trata 20 mil litros en 45 minutos; D en 1 hora trata 120 mil litros y la ropa $\mathrm{E}$ no puede informar porque no tiene o no puede estimar un tiempo. Se recolectaron muestras del efluente de entrada y salida en las lavanderías A y B para medir el $\mathrm{pH}$ y la turbidez, se encontró que el $\mathrm{pH}$ de entrada y salida del establecimiento A fue de 3.77 y 6.80 respectivamente, mientras que la turbidez promedio de entrada fue de 9.37 NTU y de salida. 1,9 NTU. El Proyecto B tenía su pH de entrada y salida equivalentes a 5,59 y 4,51 respectivamente, y su promedio de turbidez de entrada de 111,3 NTU y 3,13 NTU de salida. Estos datos apalancan y sintetizan la investigación de manera que permite comparar los resultados de las prácticas industriales con las indicaciones ya establecidas por la normativa.

Palabras Clave: Industria Textil, Remediación de Efluentes, Agreste Pernambuco, Sostenibilidad, Colorantes Industriales.

\section{ABSTRACT}

Industrial laundries are responsible for processing denim pieces that undergo chemical and physical processes, thus generating polluting loads that contribute to the current status of the textile industry as the second most polluting sector in the environment. The remediation of these loads is essential for the reuse of water or for disposal. Thus, it was observed in the scientific literature possible ways to mitigate this polluting load, interviews were also conducted with five laundries (A, B, C, D and E) within the Agreste Pernambuco region, together with the application of a questionnaire to survey data on the methods already used by them, what is the degree of efficiency and what would be the final destination of both the waste sludge and the treated water. The treatment system applied in the ETE of some of these laundries is the continuous process system, in addition to this process, there is also the batch system. These companies usually use equipment and materials such as: Compressor, pump, tanks, chemical agents, sand filter to treat their effluent. The load removal time varies in each laundry, in company A 10 thousand liters are treated in 20 minutes; in B between 1 hour and 1 hour and a half 15 thousand liters are treated; company $\mathrm{C}$ treats 20 thousand liters in 45 minutes; D in 1 hour treats 120 thousand liters and laundry E cannot inform because it does not have or cannot estimate a time. Samples were collected from the inlet and outlet effluent in Laundries $\mathrm{A}$ and $\mathrm{B}$ to measure the $\mathrm{pH}$ and turbidity, it was found that the inlet and outlet $\mathrm{pH}$ of establishment $\mathrm{A}$ was 3.77 and 6.80 respectively, while the average turbidity was input was 9.37 NTU and output 1.9 NTU. Project B had its input and output pH equivalent to 5.59 and 4.51 respectively, and its input turbidity average of $111.3 \mathrm{NTU}$ and $3.13 \mathrm{NTU}$ output. These data leverage and synthesize the research in a way that makes it possible to compare the results of industrial practices with the indications already established by the regulations.

Keywords: Textile Industry, Effluent Remediation, Agreste Pernambuco, Sustainability, Industrial Dye.

\section{INTRODUÇÃO}

A indústria têxtil é considerada como um dos principais setores tradicionais complexos devido a sua longa cadeia produtiva (ABIT, 2017), além de ser um dos ramos importantes dentro do setor econômico, pois atende necessidades, fomenta a Indústria da moda e ainda é 
geradora de empregos. As lavanderias têxteis fazem parte dessa cadeia de produção lidando com o beneficiamento dos jeans que antes usado por ser um material resistente no trabalho, com o passar do tempo foi cada vez mais ganhando seu espaço na moda. Entretanto, apesar desse cenário vistoso as Indústrias têxteis são responsáveis pelo uso de altos volumes de água, já que esse é o seu principal insumo, e produtos químicos em seus processos (ROBINSON, et al. 2001) além de gerar resíduos sólidos em longa escala (AVELAR, et al. 2016). Após o processo de beneficiamento das peças ocorre o despejo de líquidos que é chamado de efluente (CONAMA, 2011). O lançamento de efluente possui alto índice de poluição de carga, sendo por vezes descartados de forma inadequada no meio ambiente por não possuírem um tratamento adequado para a possibilidade de descarte nos corpos d'água (SILVA, et al. 2018). Logo, destaca-se a relevância de métodos eficazes e eficientes para a remoção de corantes industriais que podemos discutir esses métodos em três categorias: Biológico, Físico e Químico sendo esses dois últimos os principais (ROBENSON, et al. 2001).

\section{FUNDAMENTAÇÃO TEÓRICA}

Indústrias têxteis além de serem responsáveis pela maior parte de corantes utilizados geram grandes quantidades de resíduos líquidos industriais que podem conter materiais orgânicos e inorgânicos juntos de metais pesados as gerações desses efluentes líquidos se encontram na área do beneficiamento do tecido (CPRH, 2001.). Com isso alguns problemas são acarretados, como o alto uso e alta poluição da água no mundo (CHEN, et al.,2017) e ainda mais o agravamento dos gases de efeito estufa, visto que, essas indústrias são responsáveis pela emissão de 8 a 10\% de gases (ZOZ, 2020).

O Parque têxtil brasileiro vem ganhando relevância no cenário mundial por suas dimensões e suas técnicas de produção, sendo já considerado o quarto maior no setor industrial de tecidos do mundo, e o terceiro maior consumidor de denim (ABIT, 2017). Líder nesse cenário de confeção, Pernambuco se destaca como o maior produtor de jeans nacional do Brasil (CARVALHEIRA, 2019). Segundo a ABRAVEST (Associação brasileira do vestuário, 2020) “O Brasil produziu 341 milhões de peças jeans em 2019. Desse total, o polo produtivo de Pernambuco sustentou $17 \%$ do volume".

No setor têxtil as cidades do Agreste Pernambucano são responsáveis por cerca de 800 milhões de peças de vestuários todos os anos, tanto no comércio nacional como também internacional (PRODV,2019). Os responsáveis por esses fatores de notoriedade têxtil é o triangulo econômico configurados pelas cidades de Caruaru, Toritama e Santa Cruz do Capibaribe que juntas abrejem um total de 96 lavanderias. A produção ampla do polo no final 


\section{REMEDIAÇÃO DE EFLUENTES INDUSTRIAIS}

do ano de 2017 teve um faturamento de cerca de R\$ 3,5 bilhões (FCEM, 2020) além disso seu acrescente mercado cria oportunidade de empregos em vários setores.

$\mathrm{Na}$ liderança do setor de confecções do Agreste pernambucano surge um empecilho devido a crise hídrica e os impactos ambientais que são gerados por essas atividades nessa região do país. A crise hídrica é um dos assuntos que vem cada vez mais sendo recorrente em debates, principalmente quando se fala em sustentabilidade e lavanderias têxteis. Visto essa necessidade, muitas literaturas científicas estão se voltando para o tratamento de água e sua desinfecção (PORTILLO-VÉLEZ, HERNÁNDEZ-GORDILLO, e BIZARRO, 2017) já que outro fator recorrente é quanto ao impacto ambiental causado pelo efluente industrial gerado por corantes têxteis (ROY et al. 2018).

Nestas circunstâncias, especificando as observações sobre as regiões pernambucanas, deparam-se como uma contradição cujo diálogo reflete diretamente com o crescente sucesso do polo têxtil e o clima local que é tropical quente e seco. Diante desse cenário, em que as indústrias têxteis encontram um empecilho de tratamento (SIQUEIRA et al, 2017), devido à complexidade de cadeias produtivas geradas por águas residuais, é importante saber como essas Lavanderias vem agindo com respeito a esse assunto, pois uma das formas de contornar essa problemática de crise hídrica é fazendo o reuso da água tratada, contudo essa precisa estar adequada para ser submetida a novos procedimentos.

Lavanderias têxteis são responsáveis pelo beneficiamento do Jeans que são técnicas por meio de processos químicos e físicos que levam a possibilidade de criar diversos efeitos nos tecidos.

De acordo com Oliveira (2010, p. 177), Fluxograma é a "Representação gráfica que apresenta a sequências de um trabalho de forma Analítica, caracterizando as operações, os responsáveis e/ou as unidades organizacionais envolvidos no processo". Deste modo visando à exposição do funcionamento do método com simplicidade e lógica para obter uma visualização integrada da pesquisa e identificar os pontos fortes e fracos (OLIVEIRA, 2010) segue abaixo o fluxograma da atividade de uma lavanderia industrial (Figura 01): 
Figura 01: Fluxograma das atividades industriais da Lavanderia.

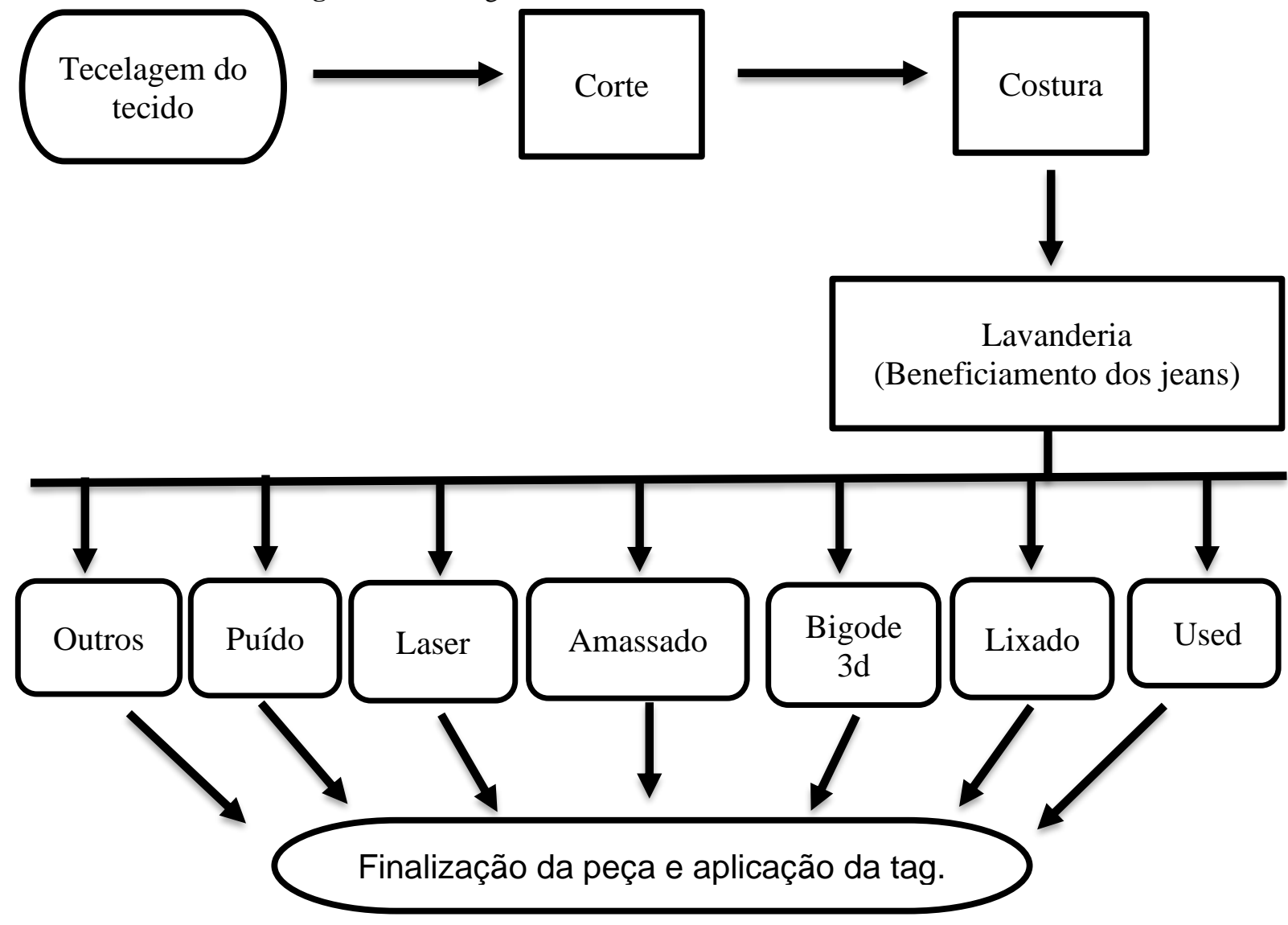

Fonte: Própria (2021)

A classificação do porte é realizada de acordo com a capacidade de produção de peças em toneladas pelas lavanderias essa capacidade de produção irá impactar na quantidade de efluente gerado e consequentemente na do lodo residual (ROTEIRO COMPLEMENTAR DE LICENCIAMENTO E FISCALIZAÇÃO PARA A TIPOLOGIA TÊXTIL, 2001). Portanto, tem-se que (Tabela 01):

Tabela 01. Licenciamento quanto ao porte das Indústrias têxteis.

\begin{tabular}{|c|c|}
\hline Porte & Capacidade de produção \\
\hline Pequena Indústria & Até $100 \mathrm{t}$ por mês \\
\hline Média Indústria & 100 até $300 \mathrm{t}$ por mês \\
\hline Grande Indústria & Acima de $300 \mathrm{t}$ por mês \\
\hline
\end{tabular}

Fonte: Roteiro complementar de licenciamento e fiscalização para a tipologia têxtil (2001. P 76.)

Entender como essas lavanderias realizam os procedimentos de remediação é de suma importância. Sendo então preciso fazer antes de tudo um levantamento quanto ao número de lavanderias registradas na região (Figura 02). 
Figura 02: Lavanderias registradas no Agreste Pernambucano.

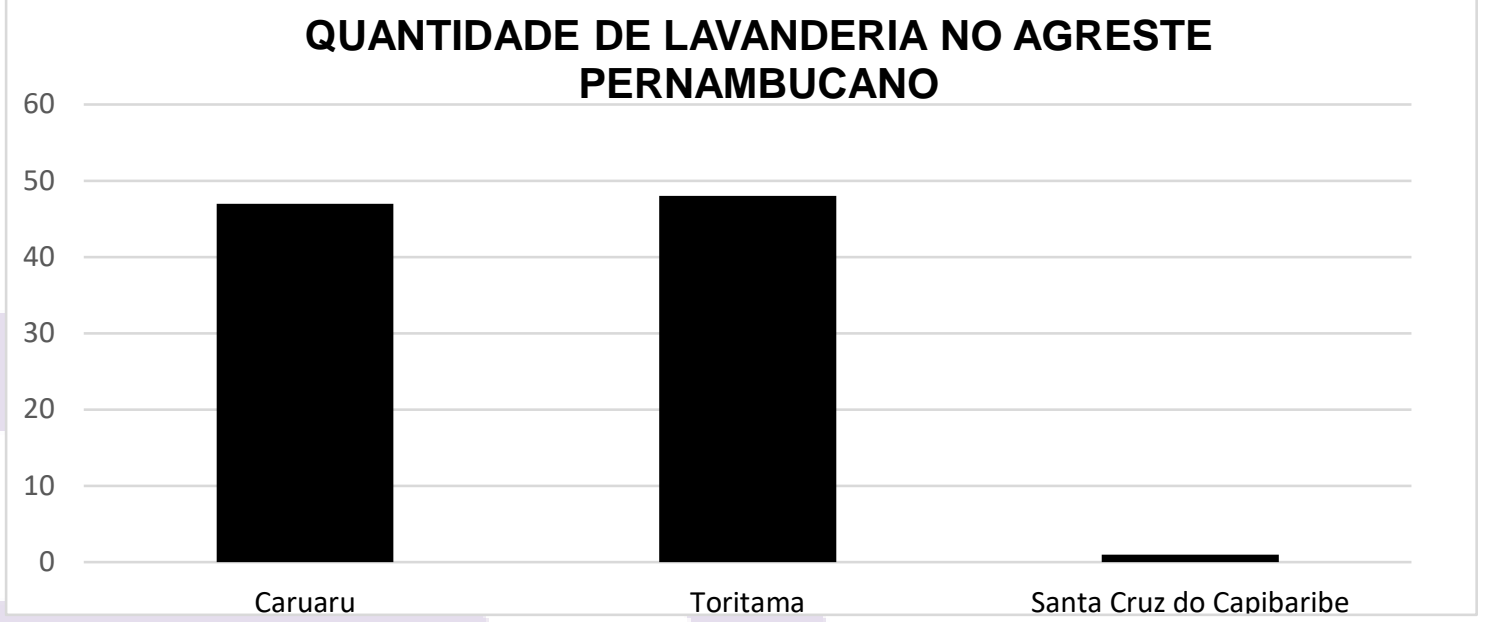

Fonte: Lista disponibilizada via e-mail pela Agência Estadual de Meio Ambiente - CPRH (2021)

A importância do tratamento de efluentes está diretamente atrelada à escassez de água potável e a poluição de cursos de água, principalmente em regiões de polos têxteis como o Agreste Pernambucano. Para o lançamento ou reaproveitamento dessa água alguns parâmetros, tais como: o PH, DQO (demanda Química de Oxigênio) DBO (Demanda Biológica de Oxigênio) Turbidez da água, precisam ser avaliados.

O DQO tem a função de apontar cargas orgânicas que estejam presentes na água, principalmente na operação de estações de tratamento de água e tributação de poluidores de águas residuais. Sendo usado mundialmente para caracterizar as diretrizes da qualidade da água (KOLB, et al., 20147). Para que a água seja tratada ela precisa passar por uma conjuntura de processos físicos e químicos, assim a água bruta se transforma em água potável e até adequado para uso humano se estiver dentro dos padrões de legalidade. Um dos métodos aplicados para essa medida é a de titulação que requer materiais como:

- Erleenmeyer

- Pipeta volumétrica

- Pêra de sucção

- Solução conhecida (Base e ácido)

- Bureta

- Indicadores

Os indicadores ácido-base são substâncias que mudam de cor na presença de um ácido ou de uma base. O procedimento consiste em colocar uma solução conhecida (ácida ou básica) na bureta e a solução que se deseja encontrar no Erlenmeyer e adicionar uma quantidade de 
indicador. Ao abrir a torneira da bureta, começara a reação. A titulação termina quando é evidente a mudança de cor da solução do Erlenmeyer. A coloração obtida indica se o meio é ácido ou básico.

Turbidez é um parâmetro físico, que pode apresentar partículas em suspensão (SAMAE). Pode ser medido por meio do turbinímetro, sendo a sua unidade dada pela nefelometria, ou seja, pela sigla UNT. Segundo a SAMAE (Serviço de Autônomo Municipal de Água e Esgoto), “A água de tratada deve apresentar turbidez menor que 0,5 UNT, para que o processo de desinfeção seja eficiente e para atendimento do padrão de potabilidade vigente".

O parâmetro de pH é químico sendo determinado pela concentração de íon de hidrogênio $\left(\mathrm{H}^{+}\right)$e indica a acidez, neutralidade ou basicidade de uma solução. Na Resolução do CONAMA N 430, de 13 de maio de 2011, a Seção II, dispõe sobre as condições e os padrões de lançamento de efluentes de qualquer fonte poluidora que for ser lançada em corpo receptor. De acordo com essa norma vigente o pH pode variar entre 5 e 9 (2011, p. 4).

O denim é um tecido sendo o mais comum o índigo blue, por causa do corante azul utilizado (ABNT, 2012). Esse corante é sintético, antes era obtido pela planta Ingigofera tinctoria, contudo com o avanço de pesquisas e tecnologias foi possível torná-lo sintético (MOREIRA, 2019). O constate contato com esses corantes podem trazer nocividades a saúdes dos seres vivos, por causa da estabilidade química e complexa degradabilidade (ARAÙJO; RODRIGUES, 2019). Os corantes que estão presentes nos efluentes industriais são visíveis devido ao seu brilho, quando liberados no meio ambiente são causadores de uma proporção da poluição da água (ROBINSON, et a., 2001). Segundo GUSMÃ (2011), podemos separar os corantes em:

- Corantes básicos: Ou corantes Catiónicos são solúveis em água e fornecem cátions coloridos;

- Corantes Diretos: Ou corantes Aniónicos são solúveis em água e apresentam afinidades por fibras celulósicas;

- Corantes Dispersos: não são iônicos, e são insolúveis em água sendo aplicados em altas temperaturas e pressão;

- Corantes Reativos: Aqui ocorre reações químicas através de nucleofílico. Sendo sua principal vantagem promover grande estabilidade na cor do tingimento do tecido. 
O sistema por batelada é feito de maneira descontinua, em cada tempo ou batelada é adicionado matérias-primas e reagentes possibilitando a retirada de resíduos sólidos da água de um volume superior à do sistema Contínuo, porém apresenta um processo mais demorado (GOMES,2018) aqui a variável tempo é importante devido a variação da temperatura e a concentração do reator (PROPEQ,2020), um exemplo desse sistema empregado é em remoção de Demanda Bioquímica de Oxigênio e regulação de pH (MENDONÇA, et al. 2015).

A mão de obra humana é utilizada de forma mínima sendo uma forma sem interrupções, mas não possui uma boa eficiência em tratamentos com agentes contaminantes (GOMES,2018) nesse caso a temperatura e vazão não iram ter grandes mudanças (PROPEQ, 2020). Um exemplo desse sistema é mostrado em remoção de alumínio (OLIVEIRA, 2013).

O processo de tratamento desses efluentes pode ser dado através de processos físicos, químicos, biológicos ou uma combinação entre esses três. Atualmente, o mais utilizado é a combinação físico-químico, no entanto, dois fatores são recorrentes nesse tipo de procedimento, o custo que tende a ser muito alto, e também um extenso acúmulo de lodo. De acordo com Robinson et al. (2000, p. 247), "Há uma necessidade de encontrar tratamentos alternativos que sejam eficazes na remoção de corantes de grandes volumes de efluente a um baixo custo [...]". Dessa maneira, deve-se ser analisado outras formas de ligações físico-químicas que atendam a essa demanda.

Em materiais de revisões bibliográficas sobre remoções de efluentes Industriais, observou-se a existência de uma equação para calcular a percentagem de eficiência da degradação do corante (Chandanshive et al., 2017) (Ramya et al., 2017), mostrando então a necessidade de fazer coletas de amostra do efluente bruto e do efluente tratado. A seguinte equação abaixo relaciona a degradação do corante em percentagem sendo dada pela razão entre a absolvição inicial menos a absolvição final dividida pela absolvição inicial e tendo o resultado multiplicado por 100:

$$
\text { Degradação de corante }(\%)=\frac{O D \text { Inicial }-O D \text { Final }}{O D \text { Inicial }} * 100
$$

\section{METODOLOGIA}

O Fluxograma baixo apresenta o desenvolvimento tático para a elaboração da pesquisa (Figura 03): 
Figura 03: Fluxograma do desenvolvimento tático da pesquisa.

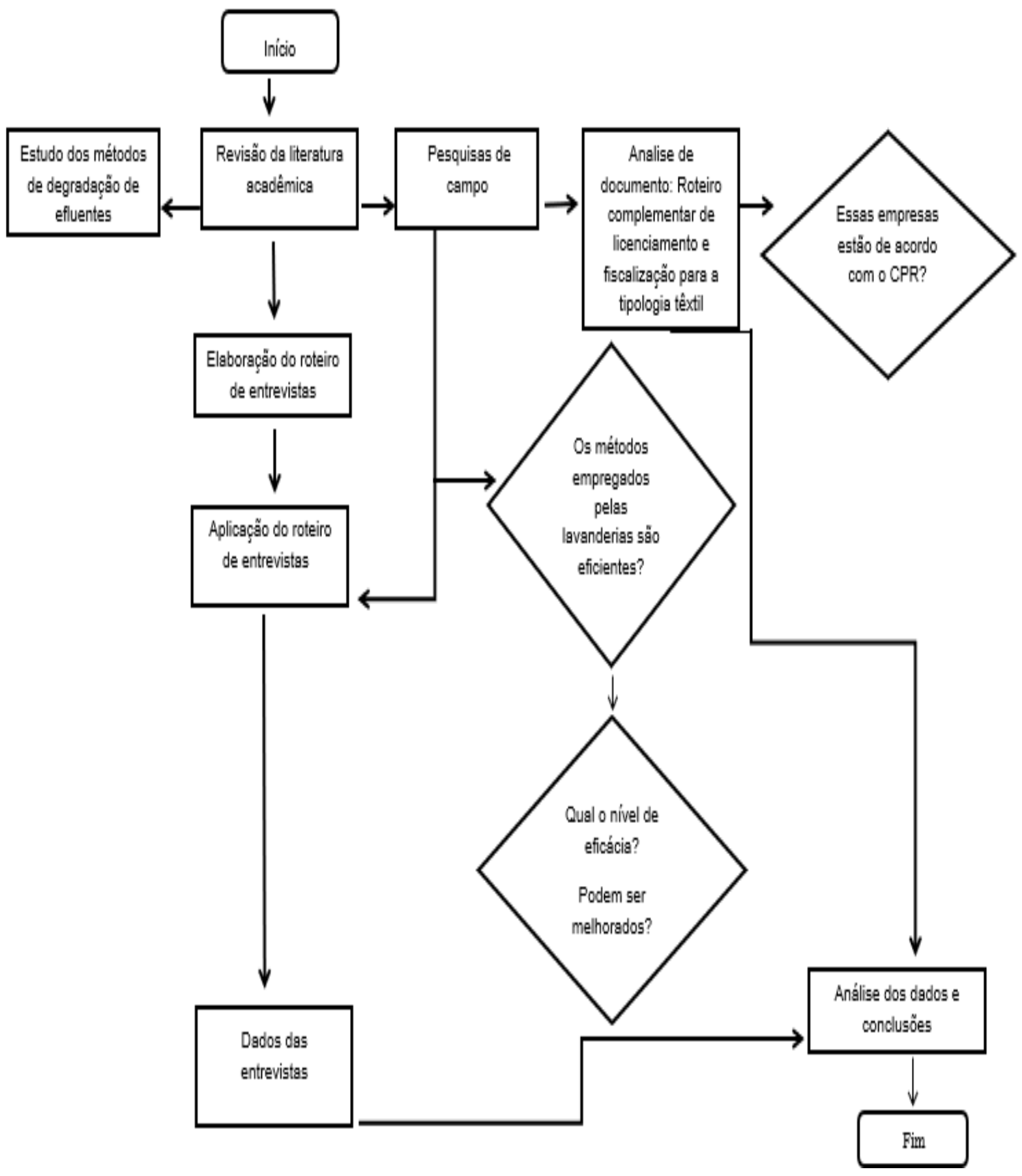

Fonte: Própria (2021)

Para aprofundar mais o conhecimento sobre o assunto e as técnicas já empregadas nas lavanderias foi realizado a confeção de um questionário que pode ser entendido como uma investigação a partir de questões especificas submetidas para a obtenção de informações que serão tornados em dados para descrever hipóteses desenvolvidas no curso da pesquisa (GIL, 2008). Para submeter esse questionário foi então realizado uma entrevista com os donos e funcionários destinados aos cuidados técnicos do efluente dessas empresas. 
Visitar as lavanderias foi uma parte de suma importância dentro da pesquisa para poder coletar as amostras. O primeiro passo feito foi identificar e aplicar o questionário para o levantamento de informações depois conhecer o sistema de ETA (estação de tratamento da água) de cada lavanderia para entender qual e como o sistema já era abordado dentro de cada uma delas. Durante a visita coletamos amostras, mais especificamente três amostras do efluente quando entra no ETA (Figura 04) e quando sai (Figura 05). Essas amostras foram coletas com o auxílio de pipetas descartáveis de $3 \mathrm{ml}, \log$ a após a coleta essas amostras foram ser armazenadas em tubos de plásticos de $15 \mathrm{ml}$ cada e em seu corpo marcados de caneta vermelha permanente a identificação da lavanderia (essas lavanderias serão identificadas com o nome de A, B,), esses tubos foram revestidos de papel alumínio e depois foi colocado em volta uma fita crepe com a letra de identificação da lavanderia. Os tubos foram armazenados em um suporte de isopor para não virar, e ficaram dentro de uma caixa de isopor com bolças de gelo, essa caixa estava dentro de uma bolsa térmica, para tentar manter as amostras mais refrigeradas o possível.

Figura 04: Coleta de Amostra de efluente bruto com pipeta volumétrica e tubo plástico.

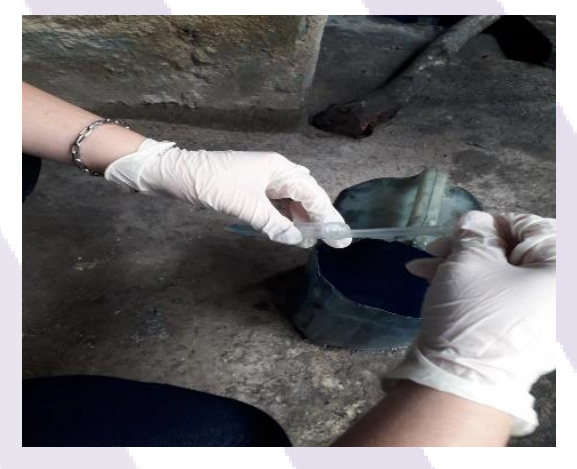

Fonte: Própria (2021)

Figura 05: Coleta de amostra do efluente tratado com pipeta volumétrica e tubo plástico.

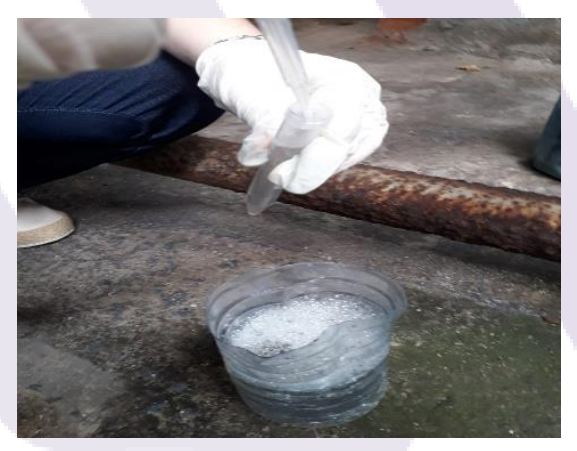

Fonte: Própria (2021)

O parâmetro de ph normalmente é medido através de um pHmetro (Figura 06): 
Figura 06: pHmetro com soluções tampões de pH, 4,7 e 10.

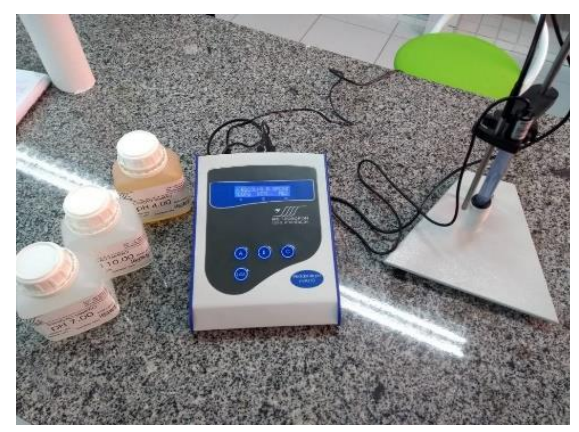

Fonte: Própria (2021)

O pHmetro é composto por um elétrodo Seletivo de vidro, sensor de temperatura e o Potenciômetro (é importante ter cuidado com o Bulbo, sempre mantendo essa parte hidratada e dentro de uma solução de cloreto de potássio e evitar tocar nessa parte de forma direta). É preciso ligar o aparelho, minutos antes. Os materiais necessários são:

- pHmetro

- Papel higiênico

- Béquer

- Água destilada

- Solução tampão 7.0 e 4.0

Para Calibrar basta tirar o elétrodo da solução de cloreto de potássio, lavar com água destilada, secar com cuidado com um papel higiênico e seguir os passos abaixo:

- Colocar a solução no Béquer

- Colocar o elétrodo e o sensor de temperatura dentro da solução. (A ponte salina precisa estar toda dentro ou o resultado não será preciso)

- Apertar o potenciômetro para calibrar

Fazendo esses mesmos passos tanto com a solução tampão de PH 7.0 como PH4.0. Lembrando de sempre lavar o elétrodo e o sensor de temperatura com água destilada e secar com um papel higiênico em intervalo de uma e outra solução. Para medir o ph da amostra:

- Lavar o elétrodo com água destilada

- $\quad$ Secar com cuidado

- Colocar no ph desconhecido

Automaticamente o aparelho já dá o resultado.

Os materiais necessários para medição de turbidez são o turbidímetro (Figura 07), papel toalha e as cubetas. Para medir basta adicionar a amostra dentro das cubetas limpar 
o corpo com papel toalha, colocar a indicação da cubeta na mesma posição indicada do equipamento e acionar o botão destinado a fazer a medição.

Figura 07: Turbidinimetro digital junto de cubetas de calibração do aparelho.

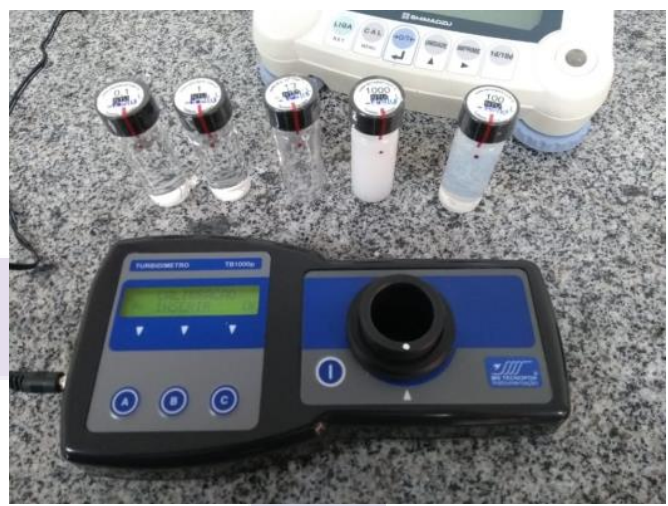

Fonte: Própria (2021)

\section{RESULTADOS E DISCUSSÃO}

Quanto ao licenciamento das lavanderias de Caruaru, Toritama e Santa Cruz do Capibaribe com base em uma lista disponibilizada pelo CPRH via e-mail, temos:

Figura 08: Licenciamento das lavanderias em Caruaru.

\section{LAVANDERIAS EM TORITAMA}

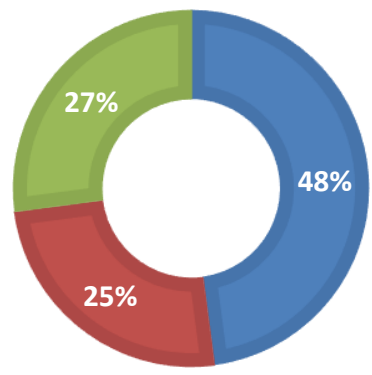

Fonte: Dados fornecidos pela CPRH, (2021). 
Figura 09: Licenciamento das Lavanderias Em Santa Cruz do Capibaribe.

\section{LAVANDERIAS EM SANTA CRUZ DO CAPIBARIBE}

- Lavanderias Licenciadas

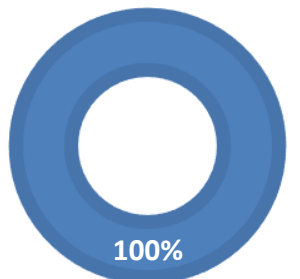

Fonte: Dados fornecidos pela CPRH, (2021)

Figura 10: Licenciamento das Lavanderias em Toritama.

\section{LAVANDERIAS EM CARUARU}

Lavanderias Licenciadas

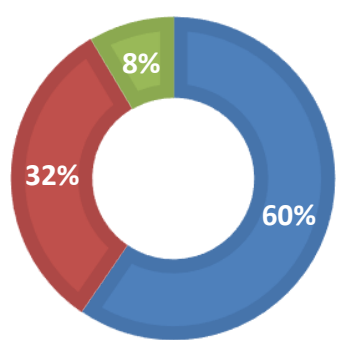

Fonte: Dados fornecidos pela CPRH, (2021)

$\mathrm{Na}$ figura abaixo temos uma comparação entre as três cidades referente ao número a situação das lavanderias quanto as licenças:

Figura 11: Situação das Lavanderias.

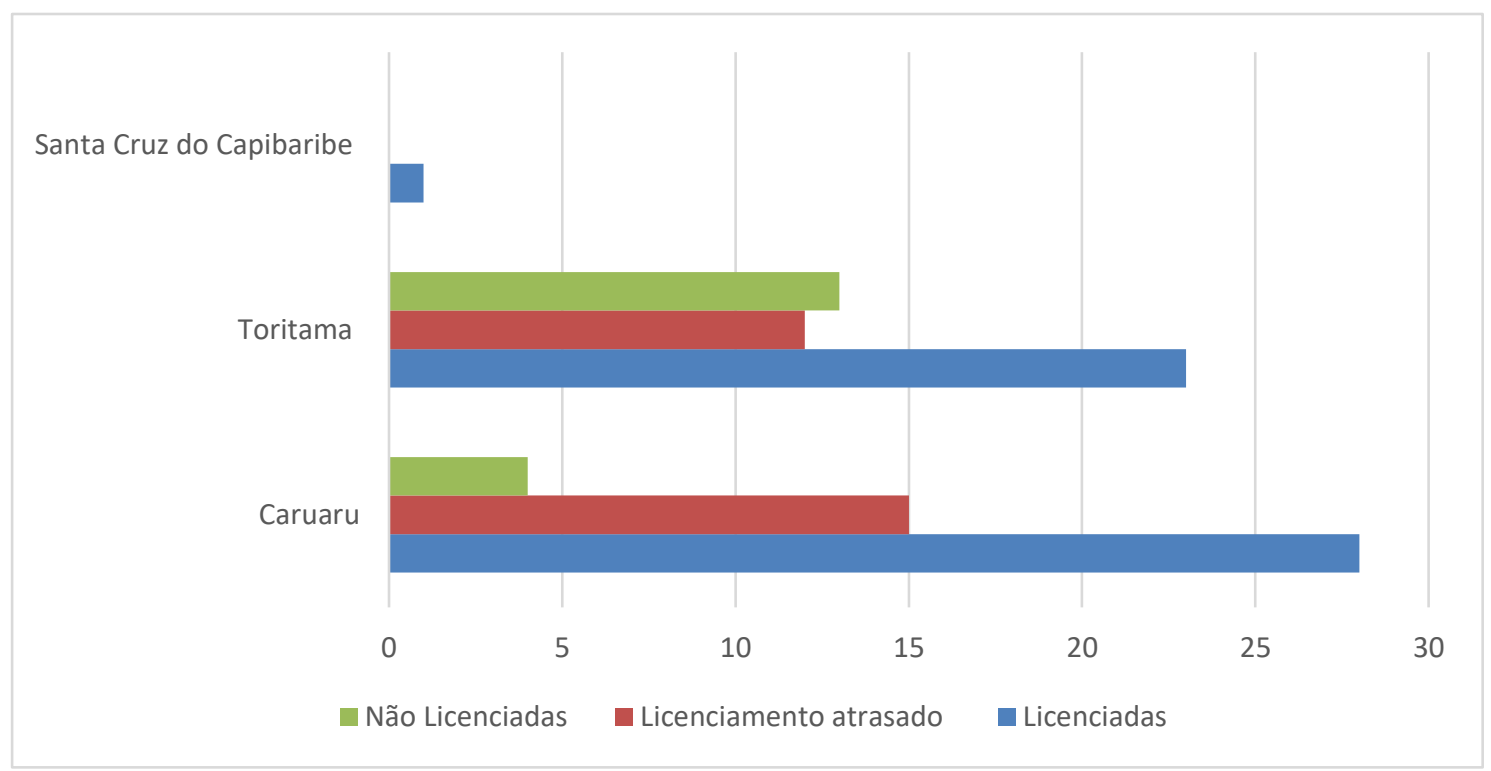

Fonte: Dados fornecidos pela CPRH, (2021) 
Pela definição que o CPRH dar sobre o porte das lavanderias e que já foi mencionado aqui nesse artigo no tópico 2.3.2 temos (Tabela 02):

Tabela 02: Determinação do porte da lavanderia pela capacidade de produção por mês.

\begin{tabular}{|c|c|}
\hline Lavanderia & Porte \\
\hline A & Pequena \\
\hline B & Pequena \\
\hline C & Pequena \\
\hline D & Pequena \\
\hline E & Pequena \\
\hline
\end{tabular}

Fonte: Própria (2021)

Visto que um dos aspectos na pesquisa era estudar os métodos de degradação de corantes foi preciso fazer um levantamento sobre quais corantes eram utilizados nas cinco lavanderias entrevistadas (Tabela 03):

Tabela 03: Corantes Empregados nos tecidos processados.

\begin{tabular}{|c|c|}
\hline Lavanderia & Corantes Utilizados \\
\hline A & Preto \\
\hline B & Não utilizam \\
\hline C & Preto \\
\hline D & Não utilizam \\
\hline E & Reativo e Direto \\
\hline
\end{tabular}

Fonte: Própria (2021)

Por meio de processos químicos e físicos a lavagem possibilita a criação de diversos efeitos no tecido. Alguns desses processos estão destacados abaixo (Tabela 04) como sendo utilizados frequentemente em cada lavanderia: 
Tabela 4: Técnicas mais utilizadas de beneficiamento dos jeans.

\begin{tabular}{|c|c|}
\hline Lavanderia & Técnicas de beneficiamento \\
\hline A & Lixado, Pistolado, Arriado \\
\hline B & Used, Amassado e Estonagem \\
\hline C & Used, Lavado e Cristal \\
\hline D & Laser e Osonio \\
\hline E & $\begin{array}{c}\text { Lixado,Laser, Bigode 3D, Estonagem, Tingimento, Clareamento, } \\
\text { Pistolado, Desengomagem }\end{array}$ \\
\hline
\end{tabular}

Fonte: Própria (2021)

Todas elas relataram que fazem o tratamento do seu efluente, esse processo visa livrar todo tipo de contaminação e evitar doenças, contudo esses procedimentos requerem tempo. $\mathrm{O}$ tempo gasto por essas lavanderias estão dispostos na tabela $\mathbf{0 5}$ :

Tabela 05: Dados do tempo gasto por cada lavanderia para a remoção do seu efluente.

\begin{tabular}{|c|c|}
\hline Lavanderia & Tempo de remoção de carga \\
\hline A & 20 min em 10 mil litros \\
\hline B & Entre $1 \mathrm{~h}$ e $1 \mathrm{~h}$ e meia em 15 mil litros \\
\hline C & 45 min em 20 mil litros \\
\hline D & $1 \mathrm{~h}$ em 120 mil litros \\
\hline E & Não informado \\
\hline
\end{tabular}

Fonte: Própria (2021)

A coleta de amostra foi submetida no pHmetro, primeiramente o efluente bruto que apresentou pH de 3.77 na lavanderia A e 5.59 na lavanderia B. Já o efluente tratado mostrou um $\mathrm{pH}$ de 6.80 na lavanderia A e 4.51 na lavanderia B. A figura 12 índica onde esses valores de entrada se encontram na escala do potencial hidrogênio. Já a figura 13 mostra os valores de saída nessa mesma faixa. 


\section{REMEDIAÇÃO DE EFLUENTES INDUSTRIAIS}

Figura 12: A imagem ilustra a indicação do ph do efluente bruto da lavanderia A e B.

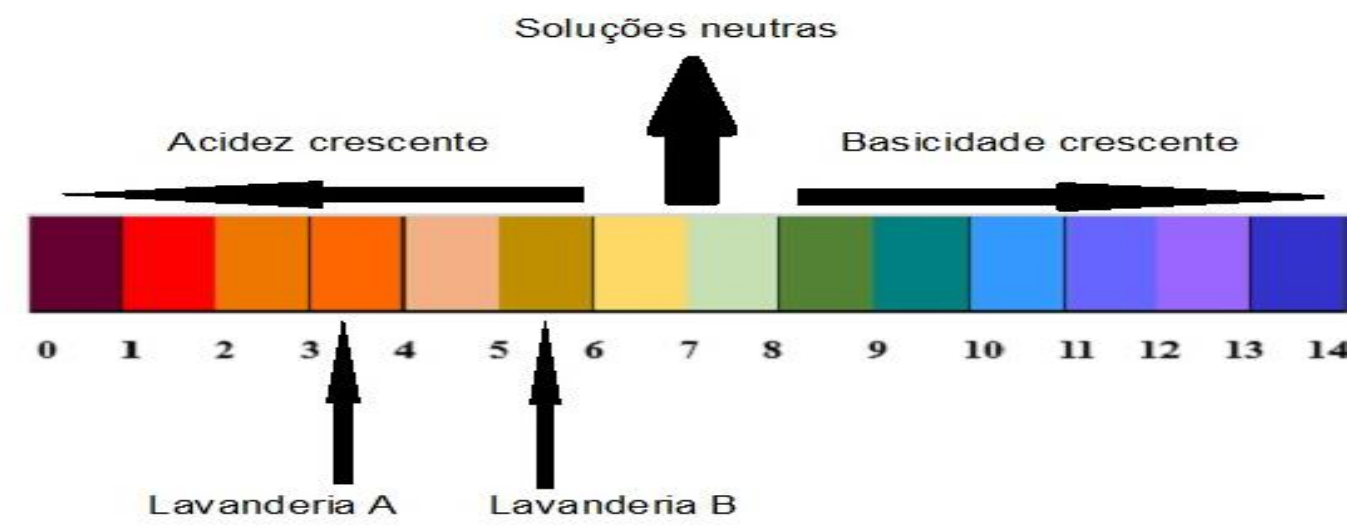

Fonte: Própria (2021)

Figura 13: A imagem ilustra a indicação do ph do efluente tratado da lavanderia A e B.

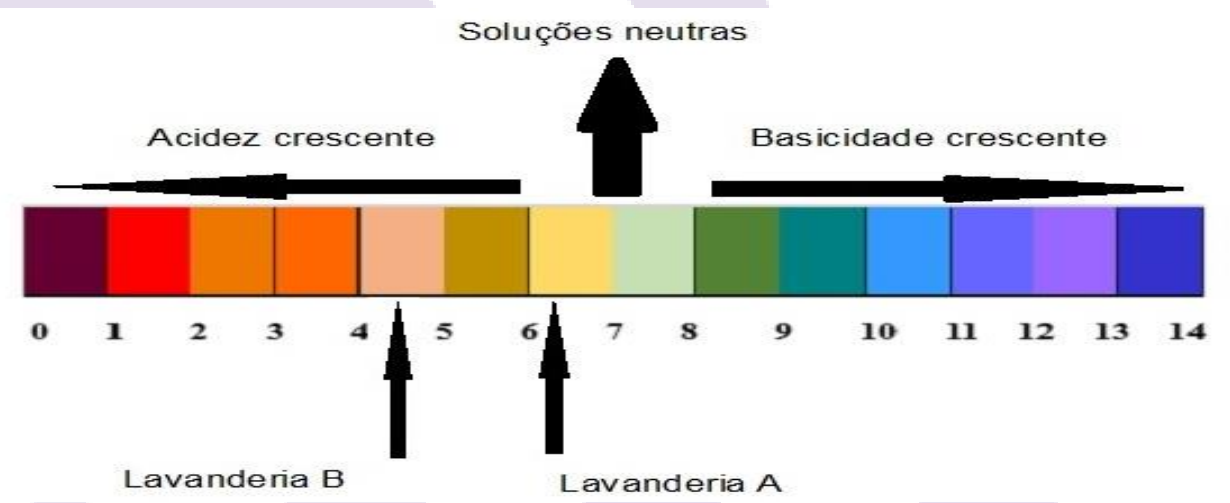

Fonte: Própria (2021)

Para realizar a medida da turbidez foi utilizado as três amostras pegas tanto do efluente de entrada como de saída. Após o registro das doze coletas foi feita uma média com as três coletas de entrada e saída de cada Lavanderia (Tabela 06).

Tabela 06: Média do resultado das amostras registradas no turbidímetro das Lavanderias A e B.

\begin{tabular}{|c|l|l|}
\hline LAVANDERIA & ENTRADA & SAÍDA \\
\hline A & 9.37 NTU & 1.9 NTU \\
\hline B & 111.3 NTU & 3.13 NTU \\
\hline
\end{tabular}

Fonte: Própria (2021)

O polo têxtil no agreste Pernambucano liderado pelas cidades de Caruaru, Toritama e Santa Cruz do Capibaribe conta com 52 lavanderias licenciadas, 27 com atrasos nos licenciamentos o que não as impossibilita de continuar a exercer a sua função como é observado na realização da entrevista com a Lavanderia B, que apesar de atrasada ainda continua com seu funcionamento normal, e com 17 lavanderias não licenciadas. Devido a capacidade de produção pode ser definido que todas as cinco lavanderias entrevistadas são de pequeno porte já que não 
chegam ou ultrapassam da quantidade 100 toneladas de peças produzidas.

A elaboração do questionário juntamente com a entrevista possibilitou os dados quanto a utilização de corantes nessas lavanderias onde quatro delas não utilizam ou utilizados de forma rara o corante preto, apenas na lavanderia E é utilizado constantemente os corantes diretos e reativos. Quanto as técnicas de beneficiamento dos jeans são usadas: Lixado, Pistolado, Arriado, Amassado, Used, Lavado, Cristal, Laser, Osonio, Bigode 3D, Estonagem, Tingimento, Clareamento, Desengomagem sendo a lavanderia E a que mais se utiliza de beneficiamentos.

A Coleta de amostra foi importante para averiguar se os métodos do sistema de tratamento aplicado na ETE de algumas dessas lavanderias que o mais comumente é o sistema por processo contínuo, são eficazes e eficientes. Essas empresas costumam utilizar para fazer o tratamento do seu efluente equipamentos e materiais como: Compressor, bomba, tanques, agentes químicos. O tempo de remoção de carga vária justamente devido a variáveis como a técnica de beneficiamento dos jeans que será usada e os equipamentos que serão empregados para fazer aquele tratamento.

Quatro dessas lavanderias reutilizam a sua água tratada apenas a lavanderia E encaminha em um dia sua água para um barreiro onde é misturada com a água da compensa e no outro dia realiza o descarte da água. Como as coletas de amostras foram feitas nas lavanderias A e B temos que os resultados de saída de $\mathrm{pH}$ das duas foram 6.80 e 4.51, concluindo então que essa metodologia não está ajudando para adequação ao parâmetro já estabelecido que é entre 7.0 e 9.0. A lavanderia A tem $\mathrm{pH}$ de saída mais básica do que a lavanderia b que se encontra em nível maior de acidez. Quando a questão da turbidez temos a mesma situação para Lavanderia A, a média de saída foi de 1,9 NTU, ou seja, aproximadamente 4 vezes maior do que o estabelecido e da Lavanderia B de média 3,13 sendo 6,26 maior do que o estabelecido. Quanto ao descarte do lodo residual todos elas terceirizam essa parte.

\section{CONCLUSÕES}

O tecido denim pode ser colorido com diferentes tipos de corantes sejam eles à tina, reativos, dispersos, diretos, ácidos, básicos, ao enxofre, mordentes, naturais. Vale salientar que o mais comum é o uso do azul índigo, quando finalizada a peça está se torna o tão conhecido e requerido jean. Esse cenário de confecções é bastante vigente no Agreste pernambucano sendo então propicio desenvolver pesquisas sobre esse tema dentro deste setor.

De modo geral a pesquisa foi baseada em levantamentos de pesquisas científicas 
já realizadas sobe o tratamento de efluentes das lavanderias do polo têxtil no agreste pernambucano construindo assim as primeiras hipóteses. Existem 96 lavanderias no polo têxtil do Agreste pernambucano entre lavanderias licenciadas, com licenciamentos atrasados, e não licenciadas, cujos dados para essa informação foi disponibilizado pela Agência Nacional do Meio Ambiente.

Visto que os métodos empregados pelas lavanderias divergem e também possuem pouco nível de confiabilidade quanto se comparado aos parâmetros já embelecidos pesquisas devem serem realizadas para aprofundar em um método que consiga atingir o parâmetro de $\mathrm{pH}$, turbidez e uma possível medida de DQO já estabelecidos ser atendido nessas lavanderias têxteis.

\section{REFERÊNCIAS}

ABIT. O SETOR TÊXTIL E DE CONFECÇÂO E OS DESAFIOS DA SUSTENTABILIDADE. Brasília: CNI: Confederação Nacional da Indústria, 2017.

ABRAVEST. PE É O MAIOR POLO DE JEANS DO BRASIL - GBL JEANS,2020. Em ABRAVEST : <https://abravest.org.br/site/pe-e-o-maior-polo-de-jeans-do-brasil-gbl-jeans/> Acesso em 08 de junho de 2021

\section{Apostila SAMAE: Operador de Estação de tratamento de Água e Esgoto}

Apostila SEBRAE: Guia de implementação: Normas para confecção de jeans.

ARAÚJO; Henrique Nascimento, RODRIGUES; Emanuel Carlos. Verificação do perfil espectrofotométrico de soluções aquosas de corantes provenientes da lavagem de tecido jeans utilizando luz ultravioleta e percarbonato de sódio. In: Passagens: Brazilian Journal of Development. V.5. Curitiba: 2019, pp 2759-2769.

AVELAR, Nayara Vilela. et al. Evaluation of briquetes made from textile industry solid waste. In: Passagens: Renewable energy. Brasil, 2016, pp 417-424.

CARVAlheira, R. No Polo de Confecções de Pernambuco, fabricante de denim vai empregar 254 pessoas,2019. Em UOL - O melhor conteúdo:< https://jc.ne10.uol.com.br/canal/economia/pernambuco/noticia/2019/12/26/no-polo-deconfeccoes-de-pernambuco-fabricante-de-denim-vai-empregar-254-pessoas-395896.php.> Acesso em 06 de 06 de 2021.

CHANDANSHIVE, V. V., \& al. Co-plantation of aquatic macrophytes Typha angustifolia and Paspalum scrobiculatum for effective treatment of textile industry effluent.In: Passagens: Journal of Hazardous Materials. Índia :2017. p. 47-56.

CHEN, Lizhu. A process- level water conservation and pollution control performance evaluation tool of cleaner production technology in textile industry. In: Passagens: Journal of 
cleaner production. China, 2017. Pp 1137-1143.

CONAMA, Resolução $n^{\circ}$ 430, de 13 de maio de 2011, do Conselho Nacional do Meio Ambiente-CONAMA; "Dispõe sobre as condições e padrões de lançamento de efluentes, complementa e altera a Resolução $n^{\circ} 357$, de 17 de março de 2005, do Conselho Nacional do Meio Ambiiente- CONAMA"; publicada no Diário Oficial da União em 16/05/20011; Brasília, DF.

CPHR - Companhia Pernambucana de Recursos Hídricos Pernambuco. Roteiro Complementar de Licenciamento e Fiscalização para Tipologia Têxtil.Recife,2001.

FCEM. Conheça o mercado de confecções do agrete pernambucano, 2020. Disponível em FREBRATEX GROUP.Em : < https://fcem.com.br/noticias/mercado-de-confeccoes/> .Acesso em 06 de 06 de 2021

GIL, Antonio Carlos. Métodos e Técnicas de Pesquisa. 6. Ed. São Paulo: Atlas, 2008)

GOMES, Ramon. ETE- Estação de tratamento de efluentes,2018. Em: $<$ https://www.scientech.com.br/ete-estacao-de-tratamento-de-efluentes/ > Acesso em : 16 de Agosto de 2021

GUSMÃO, karla Aparecida Guimarães. Estudo de adsorção em solução aquosa de dois corantes catiônicos e de uma eteramina usando bagaços de cana modificados quimicamente. Tese de mestrado. Ouro Preto: UFOP, 2011, 107 pp.

KOLB, M.; BAHADIR, M.; TEICHGRABER, B. Determination of Chemical oxygen demand (COD) using na alternative wet Chemical method free of mercury and dichromate. In: Passagens: Water Research. Alemanha: 2017, pp 645-654.

MENDONÇA; Henrique Vieira de; et al. Sistemas Alagados Construídos em Batelada: remoção de Demanda Bioquímica de Oxigênio e regulação de $\mathrm{pH}$ no tratamento de efluentes de laticínios. In: Passagens: Ambiente e Água - Na Interdisciplinary Journal of Applied Science, Vol 10. Taubaté, 2015, pp 442 - 453.

MOREIRA, Sofia Coelho. Efeitos ecotoxicológicos dos corantes índigo sintético e natural sobre a microalga Raphidocelis Subcapitata e sobre o peixe Danio Rerio. Tese de mestrado. Sorocaba: Unesp,2019, 100 pgs.

OLIVEIRA, Letícia Raquel de; ALMEIDA, Juliana Silva M.; FRANCO JR, MOILTON R. Remoção de Alumínio em sistema contínuo por coluna de leito fixo de carvão ativado - Efeito da granulometria. In: III Congresso internacional de meio ambiente subterrâneo. Minas gerais,2013. P. 1-4

PORTILLO-VÉLEZ, N. S., Hernández-Gordillo, A., \& Bizarro, M. Morphological effect of $\mathrm{ZnO}$ nanoflakes and nanobars on the photocatalytic dye degradation. In: Passagens: Catalysis Today. Mexico, 2017. p. 106-112.

PRODV. Entenda a influência do polo têxtil no Agreste Pernambucano, 2019. Em: < https://agrestetex.com.br/entenda-a-influencia-do-polo-textil-no-agreste-pernambucano/>

Acesso em: 05 de maio de 2021. 


\section{REMEDIAÇÃO DE EFLUENTES INDUSTRIAIS}

PROPEQ. Contínuo ou batelada: qual processo escolher?, 2020. Em: < . https://propeq.com/continuo-ou-batelada/> . Acesso em: 16 de Agosto de 2021.

RAMYA, M., \& al., e.. A facile and efficient single step ball milling process for synthesis of partially amorphous Mg-Zn-Ca alloy powders for dye degradation. In: Passagens: Journal of Alloys and Compounds. Índia, 2017. p.185-192.

ROBINSON, Tim. et al. Remediation of dyes in textile efluente: a critical review on current treatment Technologies with a proposed alternative. In: Passagens: Bioresource Technology. Reino Unido: 2001, pp 247-255.

ROY, D. C., et al., e.. Biodegradation of Crystal Violet dye by bacteria isolated from textile industry effluents.In:Passagens: PeeJ, China, 2018. p.1-15.

SANTOS, et al., e.. Electro-flocculation associated with the extract of Moringa oleifera Lam as natural coagulant for the removal of reactive blue 5G dye . In: Passagens: Acta Sclentlarum. Brasil, 2016. p. 483-488.

SILVA, Jaqueline de Santana da Silva. et al. Evaluation of textile laundry effluents and their cytotoxic effects on allium cepa. In: Passagens: Environmental Science and polution Research. Brasil, 2018, pp 25:27890-27898.

SIQUEIRA, Á. N.; Lim, M.C.G; AGUIAR, W.J; SILVA, J.F.; SELVA, V.S. Jeans laundry in the municipality of toritama-pe: between production and environmental conservation. In: Passagens: ResearchGate. Brasil, 2017. P. 231-237

ZOZ, Bruna. Conheça os impactos da indústria têxtil no meio ambiente, 2020.Em <https://routebrasil.org/2020/08/14/conheca-os-impactos-da-industria-textil/> Acesso em: 15 de Agosto de 2021. 